\title{
Acid Hydrolysis of Bromazepam Catalyzed by Micelles, Reverse Micelles, and Microemulsions
}

\author{
Ferdousi Begum, ${ }^{1}$ M. Yousuf A. Mollah, ${ }^{1}$ \\ M. Muhibur Rahman, ${ }^{2}$ and Md. Abu Bin Hasan Susan ${ }^{1}$ \\ ${ }^{1}$ Department of Chemistry, University of Dhaka, Dhaka 1000, Bangladesh \\ ${ }^{2}$ University Grants Commission of Bangladesh, 29/1 Agargaon, Dhaka 1207, Bangladesh
}

Correspondence should be addressed to Md. Abu Bin Hasan Susan; susan@du.ac.bd

Received 9 December 2014; Revised 25 February 2015; Accepted 9 March 2015

Academic Editor: Yaorong Zheng

Copyright (C) 2015 Ferdousi Begum et al. This is an open access article distributed under the Creative Commons Attribution License, which permits unrestricted use, distribution, and reproduction in any medium, provided the original work is properly cited.

\begin{abstract}
Kinetics of the acid hydrolysis of bromazepam $(\mathrm{Bz})$ has been investigated in micelles, reverse micelles, and microemulcions of cetyltrimethylammonium bromide (CTAB) by spectrophotometric method. The rate of the acid hydrolysis of Bz was found to be enhanced both below and above the critical micelle concentration (CMC) of CTAB in aqueous solution. The pseudo-first-order rate constant $\left(k^{\prime}\right)$ shows an initial decrease for both low and high $\mathrm{H}^{+}$concentrations. With further increase in $[\mathrm{CTAB}]$, at low $\left[\mathrm{H}^{+}\right]$, the $k^{\prime}$ attains an almost constant value, while, at high $\left[\mathrm{H}^{+}\right]$, the $k^{\prime}$ passes through a maximum and then decreases. The kinetic data for catalysis by micelles of CTAB was interpreted with the pseudophase ion exchange (PIE) model. In CTAB/cyclohexane/1butanol/water microemulsions, as the water to surfactant ratio $\left(w_{o}\right)$ increases, the physicochemical properties and droplet sizes of microemulsions significantly change and distinct changes in reaction environment can be marked. The rate of the hydrolysis reaction exhibits excellent correlation with the physicochemical properties and droplet sizes of the microemulsions and reverse micelles of CTAB. At $\left[\mathrm{H}^{+}\right]=0.001 \mathrm{M}$, in reverse micelles and microemulsions of CTAB, the $k^{\prime}$ of the acid hydrolysis of Bz decreases sharply followed by a slight increase with increasing $w_{0}$.
\end{abstract}

\section{Introduction}

Supramolecular self-assembly, in other words, self-organization, is the spontaneous and reversible association of two or more components under equilibrium conditions into stable, structurally well-defined aggregates joined by noncovalent bonds [1]. A wide variety of nanometer or micrometer scale structures and assemblies have been generated, including micelles [2], microemulsions [2], and vesicles [3, 4]. These organizations from molecular self-assemblies to controllable architectures and materials with advanced functions may meet the requirement of many objectives in science and technology such as catalysis of chemical reactions, sensors, and electronic and electromechanical devices [5-10]. The rate of a chemical reaction significantly changes in supramolecular self-organized media, specifically in surfactant-based organized media involving hydrophobic interactions, such as micelles, reverse micelles, and microemulsions. This has resulted in a surge of interest in the kinetics of reactions involving different substrates solubilized in such organized media with a view to the fundamental understanding of the mechanism of reaction in different environments for their potential applications.

Research to date includes numerous attempts to explore the catalysis of hydrolysis reactions by supramolecular selfassembled systems such as micelles, reverse micelles, and microemulsions using a wide variety of substrates, including esters [11, 12], dyes [13-20], and drugs [11, 21-35]. Bromazepam (Bz) is used as a psychotropic drug which undergoes acid/base hydrolysis in aqueous solution and study of this reaction, within the physiological $\mathrm{pH}$ range, is of great importance because the absorption of these drugs in the gastrointestinal tract is affected by the nature of the chemical species involved.

Sodium decyl (SdeS), dodecyl (SDS), and tetradecyl (STS) sulfate have been reported to produce an inhibitory 
effect in the kinetics of the acid hydrolysis of aqueous diazepam, bromazepam, and flunitrazepam drugs, while negligible effects were observed in the cases of polyoxyethylene-23dodecanol and cetyltrimethylammonium bromide (CTAB) [24]. The presence of $N$-cetyl- $N$-ethyl- $N, N$-dimethylammonium bromide has been found to cause inhibition of the basic hydrolysis of triflusal [25]. The hexadecylphosphocholine micelles inhibit the basic hydrolysis of the indomethacin and acemetacin [26]. The presence of CTAB micelles enhances the rate of alkaline hydrolysis of penicillin [27]. The rate[surfactant] profiles for the hydrolysis of indomethacin show rate inhibition in the presence of SDS and rate enhancement in the presence of CTAB [28]. At pH 13, curcumin undergoes rapid degradation by alkaline hydrolysis in the SDS micelles whereas it is greatly suppressed in the presence of either CTAB or dodecyltrimethylammonium bromide micelle [29]. The effect of cationic surfactants with varying hydrophobic chains and with different head groups and anionic surfactant (SDS) on the rate of alkaline hydrolysis of the carsalam and its $N$-substituted derivatives have been investigated by Al-Ayed et al. [30]. The plots of observed rate constant $\left(k_{\mathrm{obs}}\right)$ versus [surfactants] for degradation of indomethacin under alkaline condition were curved with negative slopes for ethoxylated lanolin, polysorbate 80; but, with the cetrimonium bromide, the plots showed a marked positive change in $k_{\mathrm{obs}}$ as the [surfactant] passed through the CMC [31]. The intramolecular degradation of Cephaclor was catalyzed 25 -fold by micelles of CTAB [32]. The rate of the hydrolysis of isatin and its derivatives of different hydrophobicities increased on increasing the [cetyltrimethylammonium chloride] and, after reaching a maximum, it started decreasing: conversely, micelles of SDS inhibited the rate of hydrolysis of isatin and its derivatives [33]. Cationic micelles enhanced the rate of alkaline hydrolysis of acetylsalicylic acid and trifusal at low surfactant concentrations, although inhibited the reactions at high surfactant concentrations, while anionic micelles show a catalytic effect and zwitterionic and nonionic micelles show inhibitory effect at all concentrations [34]. The basic hydrolysis of carbofuran was catalyzed in the presence of colloidal aggregates with positive surface charge and large inhibition by anionic and nonionic surfactants [35].

In spite of numerous studies, there have been no reports on the investigation of the kinetics of the acid hydrolysis of $\mathrm{Bz}$ in reverse micelles and microemulsions. To understand the mechanism of this reaction under different reaction environments, microemulsion may serve as a very potential medium and kinetic studies need to be systematically and intensively conducted for its exploration. In the present work, we investigated the kinetics of the acid hydrolysis of $\mathrm{Bz}$ in absence and presence of micelles, reverse micelles, and microemulsions of CTAB and the kinetic results in these different media have been compared with those in aqueous solution. In addition, kinetic profile for the reaction catalyzed by $\mathrm{CTAB}$ was treated quantitatively by pseudophase ion exchange (PIE) model. We have also studied the physicochemical properties and droplet sizes of reverse micelles and microemulsions of $\mathrm{CTAB}$ and correlated the physicochemical properties and $Z$-average diameters with kinetic results of the acid hydrolysis of $\mathrm{Bz}$.

\section{Materials and Methods}

2.1. Reagents. Bromazepam (generously received from ACI Limited), cetyltrimethylammonium bromide (CTAB) (E. Merck), 1-butanol (Merck), cyclohexane (Merck), sodium hydroxide $(\mathrm{NaOH})$, and hydrochloric acid $(\mathrm{HCl})$ solution were each reagent grade material and used as received without further purification.

\subsection{Preparation of Microemulsions and Reverse Micelles of} $C T A B$. The CTAB/1-butanol/cyclohexane/water microemulsions were prepared at fixed CTAB (20\% wt.) and cyclohexane ( 0 and $3.4 \%$ wt.) with different water and 1-butanol contents that ranged from high water to high alcohol content using deionized double distilled water following the procedure reported earlier [36].

2.3. Apparatus. Kinetic measurements and spectral analysis were carried out in a double beam Shimadzu UV-visible spectrophotometer model UV1650C (equipped with a thermoregulated cell compartment) and a rectangular quartz cell of path length $1 \mathrm{~cm}$ was used throughout the investigation. The reproducibility of the results in all cases has been checked through replicate measurements. The results, reproducible in the range of $\pm 1 \%$, were only used for kinetic profiles. Specific conductivities, viscosities, and refractive indices of different CTAB microemulsions and reverse micelles were measured with a Jenway 4510 conductivity meter (equipped with a diptype precalibrated cell), AntonPaar-Lovis $2000 \mathrm{M} / \mathrm{ME}$ microviscometer (measure viscosity by rolling ball principle with an accuracy of $\pm 10^{-6} \mathrm{mPa} \mathrm{s}$ ), and Abbemat 300 refractometer (high resolution optical sensor), respectively. The $Z$-average diameters of different $\mathrm{CTAB}$ microemulsions and reverse micelles droplets were measured using a Zetasizer Nano ZS90 (ZEN3690, Malvern Instruments Ltd., UK) by dynamic light scattering (DLS) method. The particle size detection limit was about $0.3 \mathrm{~nm}-5 \mu \mathrm{m}$ (diameter) and accuracy of the $Z$ average diameter determined has been $\pm 2 \%$. A He-Ne laser of $633 \mathrm{~nm}$ wavelength was used and the measurements were made at a fixed scattering angle of $90^{\circ}$. Samples were filtered using VALUPREP $0.45 \mu \mathrm{m}$ polytetrafluoroethylene (PTFE) filter and the $Z$-average diameters were determined from cumulants mean of the intensity average of 50 runs and the reproducibility was checked from at least 3 measurements. The temperature of the apparatus was controlled automatically within $\pm 0.01 \mathrm{~K}$ by a built-in Peltier device.

2.4. Acid Hydrolysis of $\mathrm{Bz}$. The rate of acid hydrolysis of $\mathrm{Bz}$ in aqueous solution was measured spectrophotometrically by monitoring the absorbance at the $\lambda_{\max }(=235 \mathrm{~nm})$ of $\mathrm{Bz}$ with the progress of the reaction. In the cases of kinetic measurements absorbance at the $\lambda_{\max }$ of $\mathrm{Bz}$ in micelles, reverse micelles, and microemulsions of CTAB was monitored since the $\lambda_{\max }$ was found to shift slightly in the presence of these media. The kinetic studies were conducted at controlled temperature. The acid hydrolysis of $\mathrm{Bz}$ follows second-order kinetics. The hydrolysis was therefore carried out by using a large excess of $\left[\mathrm{H}^{+}\right]$(more than 10 -fold) in aqueous and 


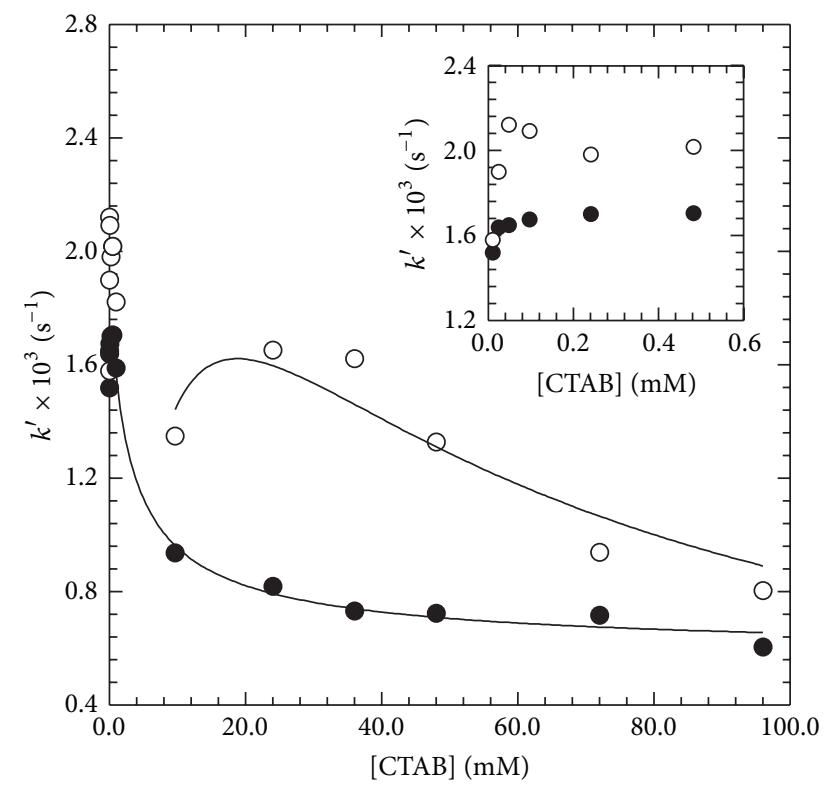

- $\left[\mathrm{H}^{+}\right](\mathrm{M})=0.001$

$\mathrm{O}\left[\mathrm{H}^{+}\right](\mathrm{M})=0.010$

FIGURE 1: The $k^{\prime}$ as a function of [CTAB] for acid hydrolysis of $2.21 \times$ $10^{-5} \mathrm{MBz}$. Inset shows the values of the $k^{\prime}$ at [CTAB] below the CMC.

different supramolecular systems of CTAB, that is, under pseudo-first-order conditions of $\left[\mathrm{H}^{+}\right] \gg[\mathrm{Bz}]$. Assuming absorbance at $235 \mathrm{~nm}$ of the reaction mixture to be due to $\mathrm{Bz}$ only, we obtain, $\ln \left[\left(A_{0}-A_{\infty}\right) /\left(A-A_{\infty}\right)\right]=k^{\prime} t$; here, $k^{\prime}$ is the pseudo-first-order rate constant, $A$ is the absorbance at any time, $t$, and $A_{0}$ and $A_{\infty}$ are the absorbance at $t=0$ and $t=\infty$, respectively, which depend on the molar absorptivity and the initial and final concentrations of the Bz. The values of $k^{\prime}$ were evaluated from a least square fit of the plot of $\ln \left[\left(A_{0}-A_{\infty}\right) /\left(A-A_{\infty}\right)\right]$ versus $t$.

\section{Results and Discussions}

3.1. Critical Micelle Concentration (CMC) of CTAB in Aqueous Solution. The variation in specific conductivity with change in concentration of $\mathrm{CTAB}$ in aqueous media CTAB was measured to determine the CMC of CTAB. The experimental specific conductivity values of CTAB lie on two straight lines and their point of intersection gave the CMC value for CTAB in aqueous solution. The $\mathrm{CMC}$ value at $25^{\circ} \mathrm{C}$ has been found to have a value of $0.87 \mathrm{mM}$ for $\mathrm{CTAB}$ in aqueous solution, which is in good agreement with literature data $[15,36]$.

\subsection{Hydrolysis in the Presence of CTAB. The $k^{\prime}$ versus [CTAB]} profile for the acid hydrolysis of $\mathrm{Bz}$ in the presence of $\mathrm{CTAB}$ is shown in Figure 1 for $\left[\mathrm{H}^{+}\right]=0.001$ and $0.01 \mathrm{M}$. The standard deviation in $k^{\prime}$ for aqueous solution was below $\pm 0.0014 \mathrm{~s}^{-1}$ and, for micelles, it was below $\pm 0.0020 \mathrm{~s}^{-1}$. From Figure 1, it is apparent that, below the $\mathrm{CMC}$, the $k^{\prime}$ increases for both low and high $\left[\mathrm{H}^{+}\right]$. For low $\left[\mathrm{H}^{+}\right]$, at high $[\mathrm{CTAB}]$ (up to the $\mathrm{CMC}$ ), the $k^{\prime}$ becomes almost constant; however, for high $\left[\mathrm{H}^{+}\right]$, the $k^{\prime}$ decreases as the [CTAB] increases further. Above the CMC, the $k^{\prime}$ shows an initial decrease for both low and high $\left[\mathrm{H}^{+}\right]$. As the $[\mathrm{CTAB}]$ continues to increase above the $\mathrm{CMC}$, the $k^{\prime}$ at low $\left[\mathrm{H}^{+}\right]$attains an almost constant value; while, at high $\left[\mathrm{H}^{+}\right]$, the $k^{\prime}$ passes through a maximum and then decreases. This corresponds to the change in reaction mechanism during the course of the reaction depending on $\left[\mathrm{H}^{+}\right]$. In fact, the mechanism of the hydrolysis of $\mathrm{Bz}$ changes with change in $\mathrm{pH}$. At high $\mathrm{pH}$, that is, low $\left[\mathrm{H}^{+}\right]$, the breakage of the ring occurs at the 1,2-amidic bonds, which is considered to be reversible and, at low $\mathrm{pH}$, that is, high $\left[\mathrm{H}^{+}\right]$, the rupture takes place in the remaining 1,2-amidic or 4,5azomethine group and the final hydrolysis products, the 2amino-5-substituted benzophenones and glycine derivatives [24], are formed.

The $k^{\prime}$ for the acid hydrolysis of $\mathrm{Bz}$ in aqueous solution at $\left[\mathrm{H}^{+}\right]=0.001$ and $0.01 \mathrm{M}$ is $1.07 \times 10^{-3} \mathrm{~s}^{-1}$ and $1.69 \times 10^{-3} \mathrm{~s}^{-1}$, respectively. Under identical experimental conditions, the $k^{\prime}$ has the value of $1.58 \times 10^{-3} \mathrm{~s}^{-1}$ and $1.82 \times 10^{-3} \mathrm{~s}^{-1}$ in the presence of $0.96 \mathrm{mM}$ CTAB (just above the CMC), while the $k^{\prime}$ has the value of $1.70 \times 10^{-3} \mathrm{~s}^{-1}$ and $2.02 \times 10^{-3} \mathrm{~s}^{-1}$ for $0.49 \mathrm{mM}$ CTAB (below the CMC) and for $\left[\mathrm{H}^{+}\right]=0.001$ and $0.01 \mathrm{M}$, respectively. It is clear that the values of the $k^{\prime}$ in presence of CTAB are higher than in aqueous solution. CTAB, thereby, enhances the acid hydrolysis of $\mathrm{Bz}$ and serves as a positive catalyst both below and above the CMC.

At very high [CTAB], the values of the $k^{\prime}$ have been found to be smaller than the corresponding value in aqueous solution for both high and low $\left[\mathrm{H}^{+}\right]$. This indicates that, at concentrations far above the $\mathrm{CMC}$ of $\mathrm{CTAB}$, the rate of reaction is ultimately inhibited. This may be explained in terms of two facts: Firstly, with increasing [CTAB], the number of micelles increases and when the number of micelles exceeds that required to solubilize all of $\mathrm{Bz}$, there is a dilution of the concentration of $\mathrm{Bz}$ per micelle as the [CTAB] is increased further. This causes a reduction in the rate constant. Secondly, the charged surface of CTAB in aqueous solution may cause the repulsion of similar-charged reactant, $\mathrm{H}^{+}$, or even the solubilization of the $\mathrm{H}^{+}$into the micelle. Such repulsion or solubilization of the $\mathrm{H}^{+}$will result in a decrease in its activity in the solution phase. An increase in the [CTAB] over that required to affect complete solubilization of the $\mathrm{Bz}$ may therefore result in a decrease in the rate constant, even for the cases where rate enhancement by micelles occurs.

In the cases of our kinetic runs, we have always used the concentration of $\mathrm{CTAB}$ as $20 \%$ wt., which corresponds to a value of ca. $0.5 \mathrm{M}$. The kinetics of the acid hydrolysis of $\mathrm{Bz}$ has, therefore, been studied in aqueous solution using $0.5 \mathrm{M}$ of CTAB and the result has been compared with those in aqueous solution. The $k^{\prime}$ in $0.5 \mathrm{M} \mathrm{CTAB}$ is lower $(0.74 \times$ $\left.10^{-3} \mathrm{~s}^{-1}\right)$ than the corresponding value in aqueous solution $\left(1.07 \times 10^{-3} \mathrm{~s}^{-1}\right)$ under identical experimental conditions. This is indicative of interaction between the micellar head groups and $\mathrm{Bz}$.

The enhancement and inhibition of the rate of the hydrolysis of Bz by CTAB micelles were treated by PIE model [37]. 
According to PIE model the apparent rate constant is given by the following equation:

$$
k^{\prime}=\frac{k_{W}\left[\mathrm{H}^{+}\right]+\left(k_{M} K_{S}-k_{W}\right) m_{\mathrm{H}}[M]}{1+K_{S}[M]} .
$$

Here, $[M]$ is the concentration of micellized surfactant which is given by $[M]=([S]-\mathrm{CMC}) / N$, where $[S]$ is the concentration of the surfactant and $N$ is the aggregation number (61 for CTAB in aqueous solution at $25^{\circ} \mathrm{C}$ ). The $k_{M}$ refers to the second-order rate constant in the micellar pseudophase. The $K_{\mathrm{Br}}^{\mathrm{H}}$ and $K_{S}$ are the ion exchange equilibrium constant and the binding constant of the substrate, $\mathrm{Bz}$, to the micelles, respectively. The fraction of micellar head groups neutralized by $\mathrm{H}^{+}$ions $\left(m_{\mathrm{H}}\right)$ were obtained by solving [37]

$$
m_{\mathrm{H}}^{2}+m_{\mathrm{H}}\left\{\frac{\left[\mathrm{H}^{+}\right]+K_{\mathrm{Br}}^{\mathrm{H}}\left[\mathrm{Br}^{-}\right]}{\left(K_{\mathrm{Br}}^{\mathrm{H}}-1\right)[M]}-\beta\right\}-\frac{\beta\left[\mathrm{H}^{+}\right]}{\left(K_{\mathrm{Br}}^{\mathrm{H}}-1\right)[M]}=0 .
$$

The experimental data were fitted to both (1) and (2) simultaneously, using $k_{M}, K_{S}$, and $K_{\mathrm{Br}}^{\mathrm{H}}$ as adjustable parameters. Results of computer simulation for the data at the concentration of $\mathrm{H}^{+}=0.001$ and $0.01 \mathrm{M}$ are shown in Figure 1. The values of $k_{M}, K_{S}$, and $K_{\mathrm{Br}}^{\mathrm{H}}$ obtained with best fitting at $\left[\mathrm{H}^{+}\right]=$ 0.001 and $0.01 \mathrm{M}$ are shown in Table 1 .

From Table 1, it is apparent that the values of $K_{\mathrm{Br}}^{\mathrm{H}}$ are independent of $\left[\mathrm{H}^{+}\right]$and the $K_{S}$ and $k_{M}$ depend on the $\left[\mathrm{H}^{+}\right]$. This may be due to the fact that as the concentration of $\mathrm{Bz}$ is constant, at low and high $\left[\mathrm{H}^{+}\right]$, the concentration of the reactant, $\mathrm{H}^{+}$, is different in the micellar pseudophase and the bulk phase.

\subsection{Hydrolysis in CTAB/Cyclohexane/1-Butanol/Water Micro-} emulsions and CTAB/1-Butanol/Water Reverse Micelles. Figure 2 represents the $k^{\prime}$ versus water to surfactant ratio $\left(w_{o}\right)$ profiles for CTAB/1-butanol/cyclohexane/water microemulsions and $\mathrm{CTAB} / 1$-butanol/water reverse micelles at $\left[\mathrm{H}^{+}\right]=$ $0.001 \mathrm{M}$. The standard deviations in $k^{\prime}$ for $w / o$ and $o / w$ microemulsions were maximum \pm 0.0056 and $\pm 0.0029 \mathrm{~s}^{-1}$, respectively, and that for reverse micelles ranged from \pm 0.0032 to $\pm 0.0050 \mathrm{~s}^{-1}$. Figure 2 shows that the rate constants are greatly affected by CTAB/cyclohexane/1-butanol/water microemulsions and CTAB/1-butanol/water reverse micelles, which is clear indication of catalysis of the acid hydrolysis of $\mathrm{Bz}$ by these organized media.

As the $w_{o}$ in CTAB/cyclohexane/1-butanol/water microemulsions and $\mathrm{CTAB} / 1$-butanol/water reverse micelles increases, the $k^{\prime}$ sharply decreases first and then becomes almost constant; however, at higher value of the $w_{o}(>50)$, a gradual increase is apparent. The rate constants attain value much higher than the corresponding value in aqueous solution under identical experimental conditions.

From Figure 2, in the region "ab" of the curve $\left(w_{o}<20\right)$, the rate constant decreases with increasing value of $w_{o}$ which should correspond to the region of reverse micelles of CTAB in 1-butanol where the incorporation of water into the CTAB reverse micelles inhibits the reaction. Part "cd" of the curve
TABLE 1: The optimized values of $k_{M}, K_{S}$, and $K_{\mathrm{Br}}^{\mathrm{H}}$ for $\left[\mathrm{H}^{+}\right]=0.001$ and $0.01 \mathrm{M}$ for acid hydrolysis of $2.21 \times 10^{-5} \mathrm{M} \mathrm{Bz}$ in micelles of CTAB using PIE model.

\begin{tabular}{lccc}
\hline$\left[\mathrm{H}^{+}\right](\mathrm{M})$ & $k_{M}\left(\mathrm{~s}^{-1}\right)$ & $K_{\mathrm{Br}}^{\mathrm{H}}$ & $K_{S}\left(\mathrm{M}^{-1}\right)$ \\
\hline 0.010 & 0.016 & 1.00 & 200 \\
0.001 & 0.370 & 1.00 & 187 \\
\hline
\end{tabular}

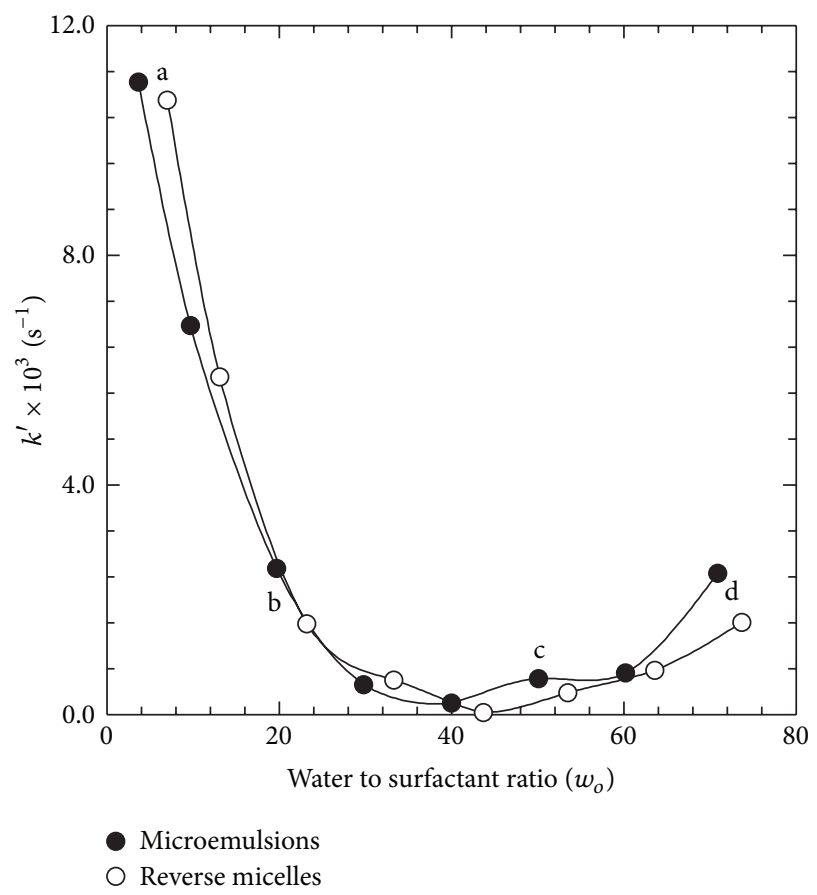

FIGURE 2: The $k^{\prime}$ versus $w_{o}$ profiles for the acid hydrolysis of $2.21 \times$ $10^{-5} \mathrm{MBz}$ in CTAB/1-butanol/cyclohexane/water microemulsions and $\mathrm{CTAB} / 1$-butanol/water reverse micelles at $\left[\mathrm{H}^{+}\right]=0.001 \mathrm{M}$.

$\left(w_{o}>50\right)$ should correspond to the reaction in CTAB micelles in water where a decrease in 1-butanol produces a slight increase in the rate of reaction. Part "bc" of the curve $\left(w_{o}\right.$ $=20 \sim 50$ ) should correspond to the cluster formation of the CTAB reverse micelles ( $w / o$ microemulsions) in 1-butanol and $\mathrm{CTAB}$ micelles (o/ $w$ microemulsions) in water that is bicontinuous microemulsions (BC).

3.4. Comparative Study for the Acid Hydrolysis of Bz in Aqueous Solution, Micelles, Reverse Micelles, and Microemulsions of $C T A B$. Figure 3 compares the $k^{\prime}$ for different supramolecular self-assembled systems based on CTAB at $[\mathrm{CTAB}]=\mathrm{ca} .0 .5 \mathrm{M}$ with that in aqueous solution under identical experimental conditions. From Figure 1, it can be seen that, at concentrations far above the $\mathrm{CMC}$ of $\mathrm{CTAB}$, the reaction rate is ultimately inhibited which may be correlated with change in binding constant between $\mathrm{CTAB}$ and acid dissociation constant of $\mathrm{Bz}$.

The $w / o$ microemulsions (lower value of $w_{o}$ ) have been found to bring about an increase in the reaction rate where high 1-butanol content dominates CTAB/1-butanol reverse micelles whereas, in $o / w$ microemulsions (higher value of 


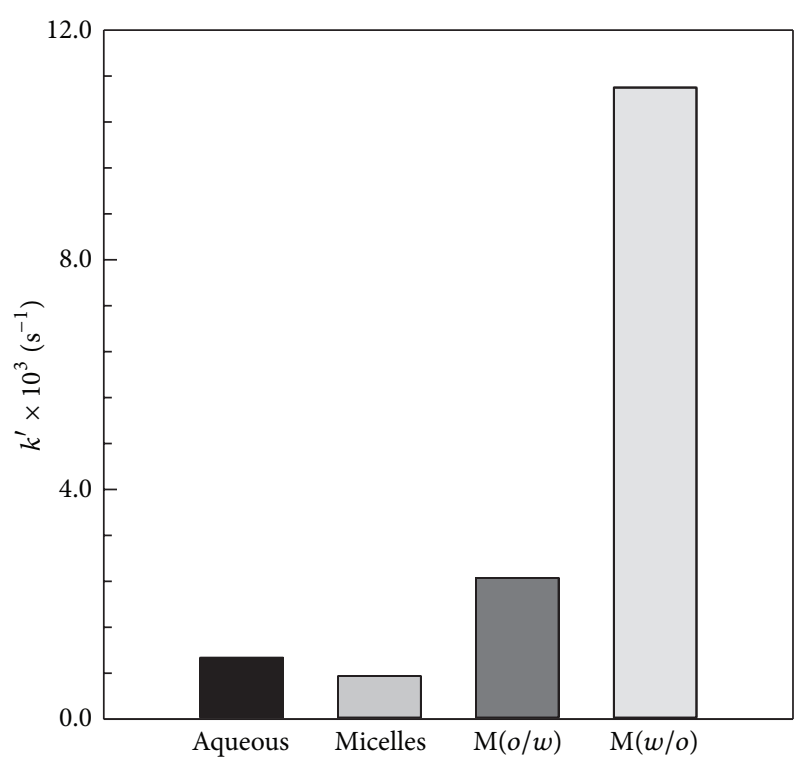

FIGURE 3: The $k^{\prime}$ for aqueous and different self-assembled systems based on CTAB; $[\mathrm{Bz}]=2.21 \times 10^{-5} \mathrm{M}$ and $\left[\mathrm{H}^{+}\right]=0.001 \mathrm{M}$. Micelles $([\mathrm{CTAB}]=$ ca. $0.5 \mathrm{M}) ; o / w\left(w_{o}=70.9\right)$ and $w / o\left(w_{o}=3.64\right)$ microemulsions.

$w_{o}$ ), the rate constant is higher as compared to aqueous solution and the corresponding micelles but lower than that in $w / o$ microemulsions. It should correspond to the region of direct $\mathrm{CTAB}$ micelles in water where the lower content of 1-butanol was incorporated into the CTAB micelles. The schematic diagram of the acid hydrolysis of $\mathrm{Bz}$ in different self-assembled systems is shown in Scheme 1.

\subsection{Physicochemical Properties of \\ CTAB/Cyclohexane/1-Butanol/Water Microemulsions and CTAB/1-Butanol/Water Reverse Micelles}

3.5.1. Viscosity. Figure 4 shows the change of viscosities with the $w_{o}$ for CTAB/1-butanol/cyclohexane/water microemulsions and $\mathrm{CTAB} / 1$-butanol/water reverse micelles. The viscosity of the microemulsions is very low, less than $120 \mathrm{mPa}$ s. In CTAB/1-butanol/cyclohexane/water microemulsions (Figure 4(a)), at $w_{o}<20$, the viscosity increases slightly while, for $w_{o}=20 \sim 50$, it increases gradually whereas, at $w_{o}>50$, a sharp increase is apparent. In CTAB/1butanol/water reverse micelles (Figure $4(\mathrm{~b})$ ), at $w_{o}<20$, the viscosity increases slightly while, for $w_{o}=20 \sim 50$, it shows a slight decrease and, at $w_{o}>50$, a sharp increase is noticeable. This increase in viscosity with the addition of water has been ascribed to the increasing diameter of water filled conduits in the bicontinuous and $o / w$ microemulsions [38]. The initial increase in viscosity profile should correspond to the aggregation and attractive interaction of water droplets in CTAB/l-butanol reverse micelles ( $w / o$ microemulsions). With further increasing $w_{o}$ up to 50 , the water and 1-butanol droplets of CTAB micelles and reverse micelles coagulate to form clusters (i.e., the bicontinuous region) in which the gradual increase for microemulsion and decrease for reverse in viscosity are apparent [39]. Above $w_{o}=50$, the sharp rise in viscosity corresponds to the 1-butanol droplets in $\mathrm{CTAB} /$ water micelles ( $o / w$ microemulsions) as the viscosity of water is higher than the 1-butanol.

3.5.2. Specific Conductivity. Figure 5 shows specific conductivities of CTAB/1-butanol/cyclohexane/water microemulsions and $\mathrm{CTAB} / 1$-butanol/water reverse micelles against the $w_{0}$. The conductivity of the microemulsions and reverse micelles increases with the $w_{o}$. This indicates an increase in the number of conducting species in the systems [39]. At lower value of the $w_{o}$, the conductivity value is low to indicate that the hydrophilic trimethylammonium ion and counterion $\mathrm{Br}^{-}$of $\mathrm{CTAB}$ in contact with the water droplets of CTAB/1-butanol reverse micelles ( $w / o$ microemulsions) are not easily dissociated. At higher value of the $w_{o}$, CTAB micelles (o/w microemulsions) are formed in water and the orientation of the CTAB changes where the hydrophilic trimethylammonium ion and the counterion, $\mathrm{Br}^{-}$, are freely dissociated in water and increase the specific conductivity. In the middle portion, the conductivity increases that should be corresponding to the network of the conductive channel (bicontinuous microemulsions) formed by the interaction of water and 1-butanol droplets of the CTAB/1-butanol reverse micelles and $\mathrm{CTAB} /$ water micelles, respectively [39].

3.5.3. Refractive Index. Figure 6 shows the change of refractive index of $\mathrm{CTAB} / 1$-butanol/cyclohexane/water microemulsions and $\mathrm{CTAB} / 1$-butanol/water reverse micelles with the $w_{o}$. The refractive index specifies the transparency of the microemulsions. With increasing $w_{o}$, the refractive index decreases monotonically. As the refractive index is a property sensitive to structural transitions, the results suggest that no structural modifications are involved [40]; that is, water and 1-butanol remain encapsulated into the CTAB/1-butanol reverse micelles (low $w_{o}$ ) and CTAB/water micelles (high $w_{o}$ ), respectively.

\subsubsection{Correlations of Physicochemical Properties of CTAB/} Cyclohexane/1-Butanol/Water Microemulsions and CTAB/1Butanol/Water Reverse Micelles with Kinetic Results of Acid Hydrolysis of Bz. As the $w_{o}$ increases, the physicochemical properties such as viscosity, density, specific conductivity, and refractive index of $\mathrm{CTAB} /$ cyclohexane/1-butanol/water microemulsions and CTAB/1-butanol/water reverse micelles change. The viscosity, density, and specific conductivity increase and refractive index decreases with the $w_{o}$. The changes in physicochemical properties with $w_{o}$ suggest that properties are dependent on different microstructure regions of reverse micelles and microemulsions. The viscosity versus $w_{o}$ profile shows different patterns for change in the $w_{0}$. Increase in viscosity at $w_{o}<20, w_{o}=20 \sim 50$, and $w_{o}>50$ corresponds to the $w / o$, bicontinuous, and $o / w$ microemulsions, respectively (Figure 4 ). Thus, increase in the $w_{o}$ causes change in reaction environment that also causes change in reaction rate of the acid hydrolysis of $\mathrm{Bz}$ (Figure 2).

Figures 2 and 4 show that as the $w_{o}$ increases, the reaction rate decreases up to $w_{o}<20$; then the rate becomes 


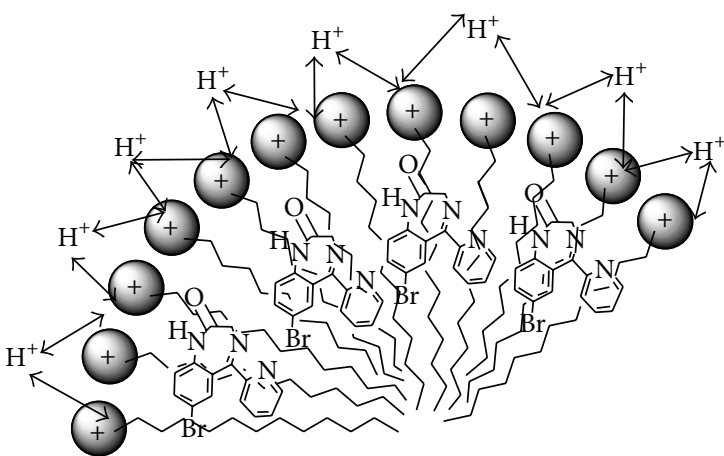

(a)

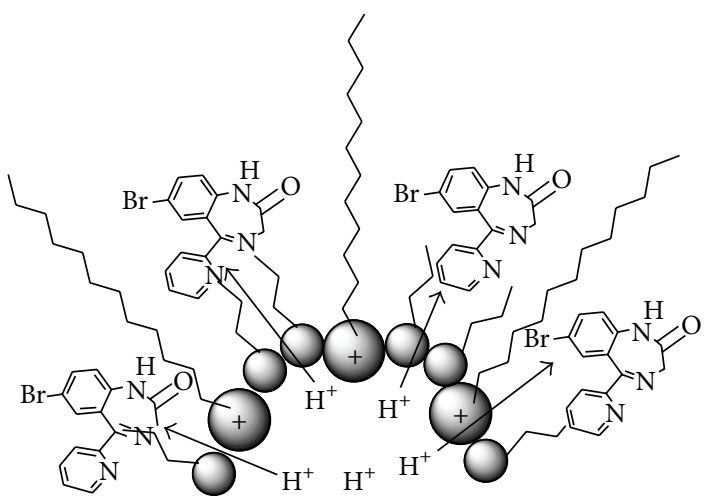

(c)

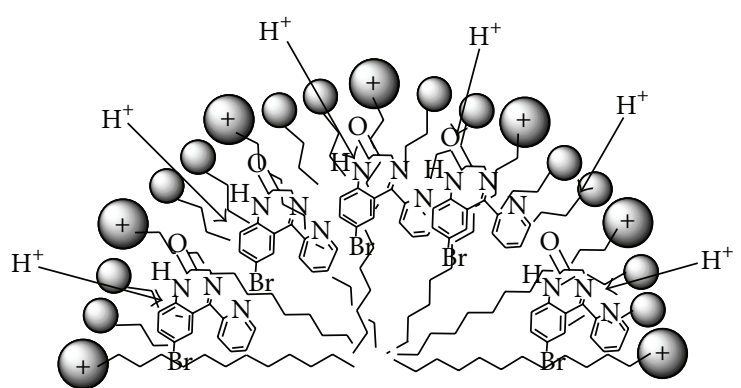

(b)
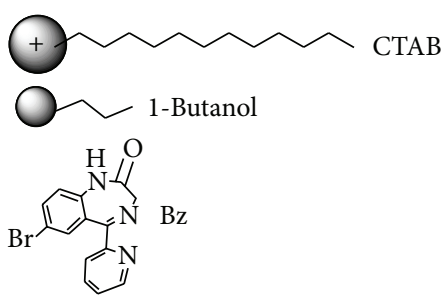

Scheme 1: Acid hydrolysis of Bz in (a) micelles $([\mathrm{CTAB}]=$ ca. $0.5 \mathrm{M}) ;(\mathrm{b}) o / w\left(w_{o}=70.9\right)$ and $(\mathrm{c}) w / o\left(w_{o}=3.64\right)$ microemulsions.

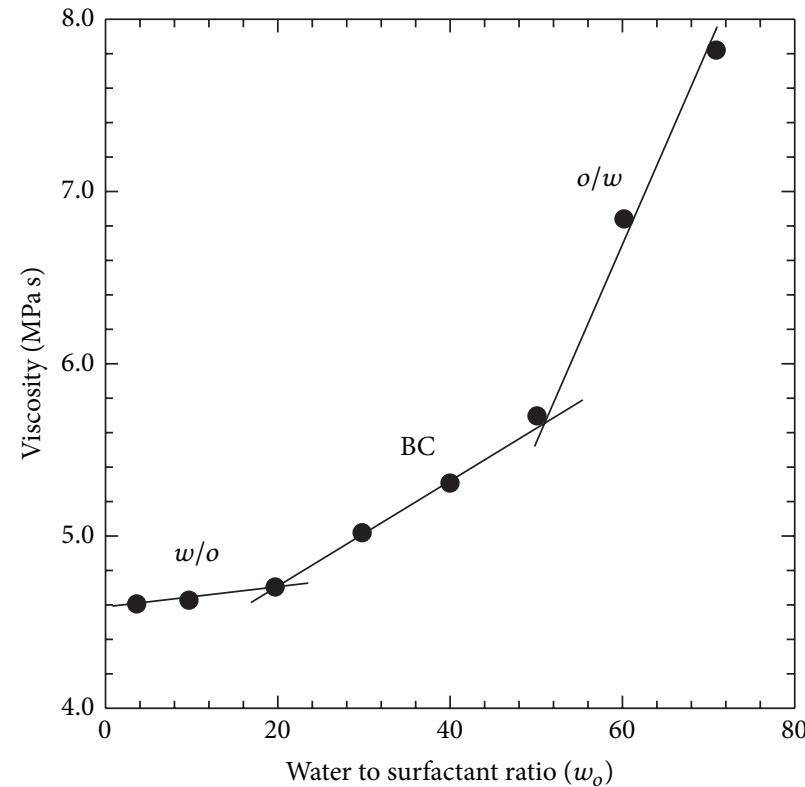

Microemulsions

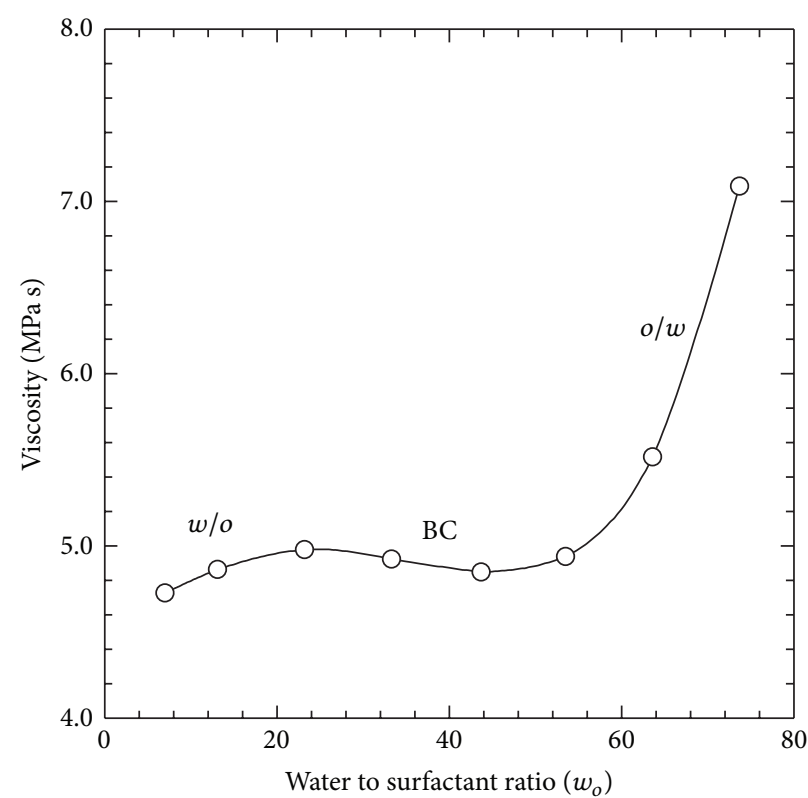

O Reverse micelles

(a)

(b)

FIGURE 4: Viscosities as a function of $w_{o}$ for (a) CTAB/1-butanol/cyclohexane/water microemulsions and (b) CTAB/1-butanol/water reverse micelles. 


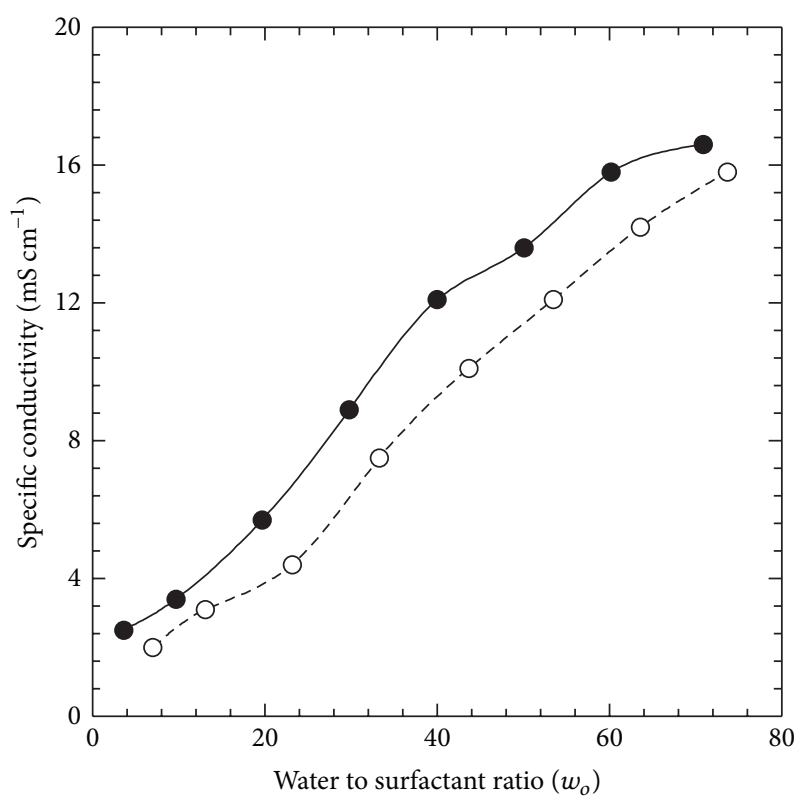

- Microemulsions

Reverse micelles

FIGURE 5: Specific conductivities of CTAB/1-butanol/cyclohexane/ water microemulsions and $\mathrm{CTAB} / 1$-butanol/water reverse micelles.

almost constant at $w_{o}=20 \sim 50$ and at $w_{o}>50$ a gradual increase is apparent which correlates well with viscosity and conductivity results. Again, the conductivity versus $w_{o}$ profile shows the increase in conductivity with increase in the $w_{o}$ which is also associated with viscosity of microemulsions and reverse micelles of CTAB. At $w_{o}>50$, the CTAB/water micelles of sufficient numbers collide and produce a channel that carries ions leading to increase in conductivity and viscosity increases due to the presence of micelle core [30]. At $w_{o}<20$, the CTAB/1-butanol reverse micelles are formed that allow transport of ions through the water that filled cores and the viscosity slightly increases due to the interaction of water droplets [39]. In the middle region, $w_{o}=20 \sim 50$, the bicontinuous microemulsions are formed where water and 1butanol droplets collide to form network structure. Thus, the viscosity increases due to the collision of different droplets and the conductivity increases for the transport of ions in the conductive channel produced by water as well as 1-butanol droplets.

3.6. Droplet Sizes of CTAB/Cyclohexane/1-Butanol/Water Microemulsions and CTAB/1-Butanol/Water Reverse Micelles. Figure 7 shows the $Z$-average diameter versus $w_{o}$ for CTAB/1butanol/cyclohexane/water microemulsions and CTAB/1butanol/water reverse micelles. The droplet sizes of all the microemulsions and reverse micelles are less than $100 \mathrm{~nm}$ [41]. It can be seen from Figure 7 that the $Z$-average diameters of $\mathrm{CTAB} / 1$-butanol/water reverse micelles are higher than the corresponding CTAB/1-butanol/cyclohexane/water microemulsions and decrease with increasing $w_{0}$. The larger size at $w_{o}=3.64$ is due to the formation of CTAB reverse

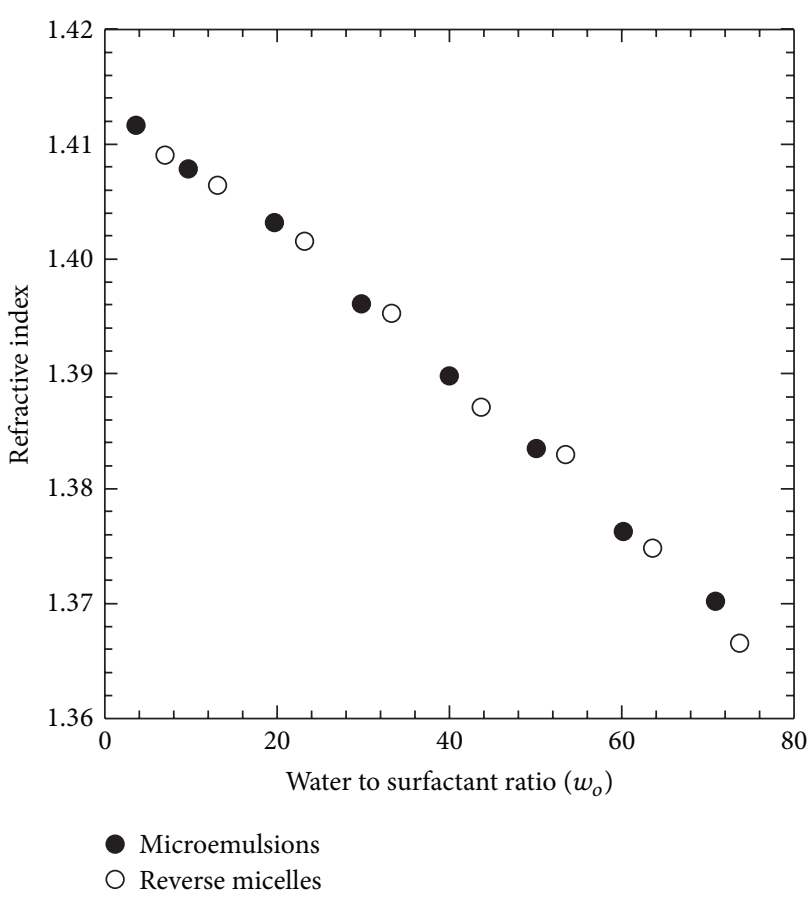

FIGURE 6: Refractive indices of CTAB/1-butanol/cyclohexane/water microemulsions and CTAB/1-butanol/water reverse micelles.

micelles ( $w / o$ microemulsions) in 1-butanol where the electrostatic repulsion between the polar heads is screened by 1butanol and facilitates the formation of aggregates as well as larger size of the droplets [42]. As the $w_{o}$ increases, the droplet sizes decrease possibly due to the decrease in the number of reverse micelles. At $w_{o}=70.9$, the droplet sizes are so small and correspond to the CTAB micelles ( $o / w$ microemulsions) in water. Additionally, in the middle region, the droplet sizes are almost constant that correspond to the transition from reverse micellar phase to micellar phase, via bicontinuous microemulsions.

The polydispersity index (PDI), a width parameter, has been calculated from a Cumulants analysis of the DLS measured intensity autocorrelation function. In general, values smaller than 0.1 indicate reasonably narrow distribution and values greater than 0.7 indicate that the sample has a very broad size distribution. The PDI values in our measurements have been evaluated for CTAB/cyclohexane/1-butanol/water microemulsions and CTAB/1-butanol/water reverse micelles. It has been found that the PDI values range from 0.107 to 0.354 and 0.226 to 0.499 for reverse micelles and microemulsions of CTAB, respectively. In all cases, the PDI values are within the range of 0.1-0.7 which indicates that the droplets of reverse micelles and microemulsions are reasonably uniform in their distribution.

The standard deviations in $Z$-average diameters, $d$, of $\mathrm{CTAB} /$ cyclohexane/1-butanol/water microemulsions and CTAB/1-butanol/water reverse micelles have been calculated and these depend on the $w_{o}$ for all cases, such as $w_{o}=3.64(d=$ $2.72 \mathrm{~nm})$ and $w_{o}=70.9(d=0.30 \mathrm{~nm})$; the standard deviations in $Z$-average diameters of microemulsions were \pm 0.682 and 


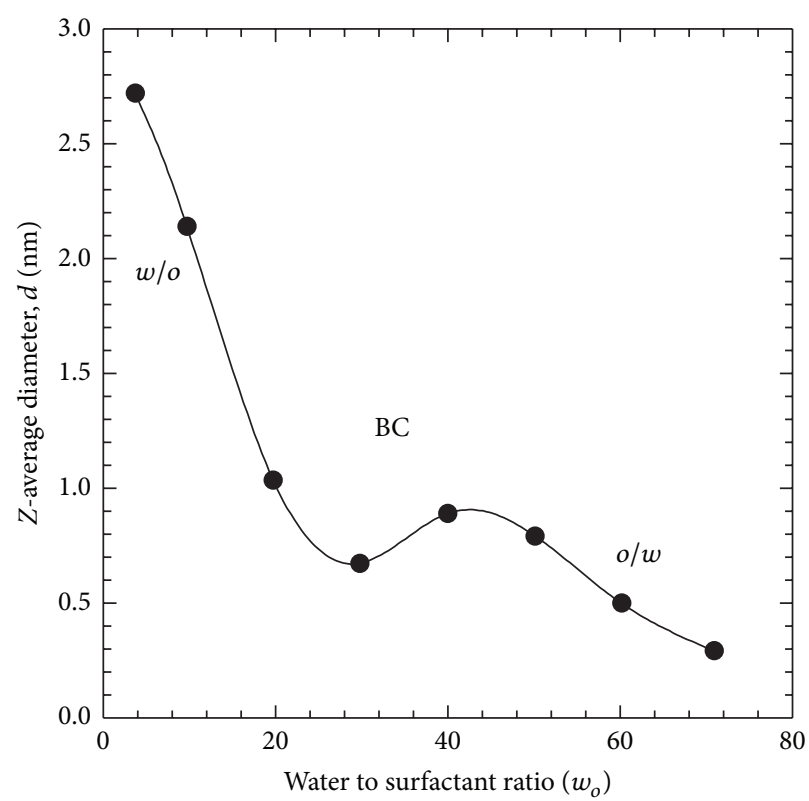

Microemulsions

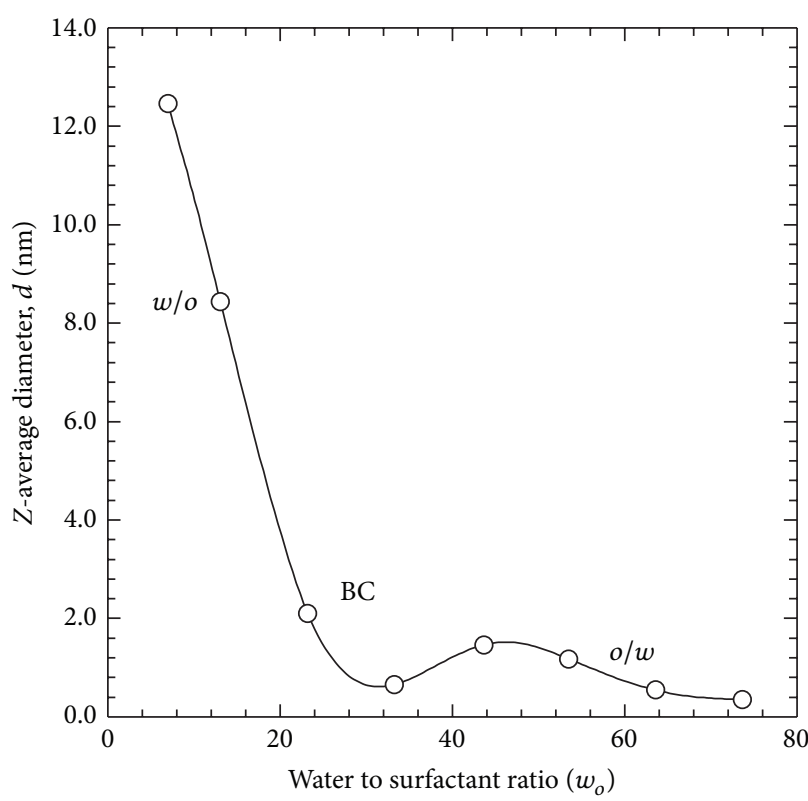

Reverse micelles

(a)

(b)

FIGURE 7: Z-average diameters of (a) CTAB/1-butanol/cyclohexane/water microemulsions and (b) CTAB/1-butanol/water reverse micelles.

$\pm 0.004 \mathrm{~nm}$, respectively, while at $w_{o}=7.00(d=12.46 \mathrm{~nm})$ and $w_{o}=73.7(d=0.35 \mathrm{~nm})$, the standard deviations in $Z$-average diameters of reverse micelles were \pm 0.614 and $\pm 0.003 \mathrm{~nm}$, respectively. Thus, for both reverse micelles and microemulsions of CTAB, at high value of $w_{o}$, the results tend to be very close to the expected values that indicate relatively narrow distribution of droplet sizes and, at low value of $w_{o}$, the results are spread out at a relatively wider range of values.

3.7. Correlation of Droplet Sizes of CTAB/Cyclohexane/1Butanol/Water Microemulsions and CTAB/1-Butanol/Water Reverse Micelles with Kinetic Results of Acid Hydrolysis of Bz. The droplet sizes of the CTAB/cyclohexane/1-butanol/water microemulsions and $\mathrm{CTAB} / 1$-butanol/water reverse micelles as well as the rate constants of acid hydrolysis of $\mathrm{Bz}$ decrease with increasing $w_{o}$ as shown in Figures 2 and 7. For lower values of $w_{o}$ (larger droplet sizes and less viscous media), the values of the $k^{\prime}$ are higher due to the presence of CTAB/1butanol reverse micelles which accelerate the reactions. In contrast, the formation of CTAB/water micelles at higher $w_{o}$ values (smaller droplet sizes and more viscous media) inhibits the reaction and lowers the reaction rate. The bicontinuous microemulsions are formed for intermediate values of the $w_{o}$ where both water and 1-butanol droplets merge to provide complex microstructures and the values of the $k^{\prime}$ as well as the size of the droplets become almost constant. The rate constants for bicontinuous systems are less than the corresponding values in $w / o, o / w$ microemulsions and the aqueous solutions.

\section{Conclusions}

Micelles, reverse micelles, and microemulsions of CTAB influence the rate of the acid hydrolysis of $\mathrm{Bz}$. The kinetic profiles vary depending on the change in the reaction environment due to different assembly and orientation of the surfactants in micelles, reverse micelles, and microemulsions. In micellar solution, the profiles also exhibit $\mathrm{pH}$ dependence. The kinetic data showed good fit to the PIE model for the title reaction with reasonable values of the parameters. The $k^{\prime}$ versus $w_{o}$ profiles for CTAB/cyclohexane/1-butanol/water microemulsions and $\mathrm{CTAB} / 1$-butanol/water reverse micelles show a sharp decrease in the $k^{\prime}$ followed by a gradual increase with increasing $w_{o}$ to indicate a transition from $w / o$ to $o / w$ via bicontinuous microemulsions. The physicochemical properties and droplet sizes of these media are also greatly affected by change in the $w_{o}$ which correlates with kinetic results with change in the microenvironment for different orientations of CTAB.

\section{Conflict of Interests}

The authors declare that there is no conflict of interests regarding the publication of this paper.

\section{Acknowledgments}

The authors acknowledge financial support for a Subproject (CP-231) from Higher Education Quality Enhancement 
Project of the University Grants Commission of Bangladesh financed by World Bank and the Government of Bangladesh. Ferdousi Begum also acknowledges Bangabandhu Fellowship from the Ministry of Science and Technology of the Government of Bangladesh.

\section{References}

[1] G. M. Whitesides and B. Grzybowski, "Self-assembly at all scales," Science, vol. 295, no. 5564, pp. 2418-2421, 2002.

[2] L. F. Zhang, K. Yu, and A. Eisenberg, "Ion-induced morphological changes in 'crew-cut' aggregates of amphiphilic block copolymers," Science, vol. 272, no. 5269, pp. 1777-1779, 1996.

[3] D. E. Discher and A. Eisenberg, "Polymer vesicles," Science, vol. 297, no. 5583, pp. 967-973, 2002.

[4] B. M. Discher, Y.-Y. Won, D. S. Ege et al., "Polymersomes: tough vesicles made from diblock copolymers," Science, vol. 284, no. 5417, pp. 1143-1146, 1999.

[5] C. M. Drain, "Self-organization of self-assembled photonic materials into functional devices: photo-switched conductors," Proceedings of the National Academy of Sciences of the United States of America, vol. 99, no. 8, pp. 5178-5182, 2002.

[6] C. Du, G. Falini, S. Fermani, C. Abbott, and J. MoradianOldak, "Supramolecular assembly of amelogenin nanospheres into birefringent microribbons," Science, vol. 307, no. 5714, pp. 1450-1454, 2005.

[7] D. G. Kurth, P. Lehmann, and M. Schütte, "A route to hierarchical materials based on complexes of metallosupramolecular polyelectrolytes and amphiphiles," Proceedings of the National Academy of Sciences of the United States of America, vol. 97, no. 11, pp. 5704-5707, 2000.

[8] S. H. Park, J.-H. Lim, S.-W. Chung, and C. A. Mirkin, "Selfassembly of macroscopic metal- polymer amphiphiles," Science, vol. 303, no. 5656, pp. 348-351, 2004.

[9] E. Winfree, F. Liu, L. A. Wenzler, and N. C. Seeman, "Design and self-assembly of two-dimensional DNA crystals," Nature, vol. 394, no. 6693, pp. 539-544, 1998.

[10] D. M. Vriezema, M. C. Aragonès, J. A. A. W. Elemans, J. J. L. M. Cornelissen, A. E. Rowan, and R. J. M. Nolte, "Self-assembled nanoreactors," Chemical Reviews, vol. 105, no. 4, pp. 1445-1489, 2005.

[11] G. Stinga, D. M. Mihai, A. Iovescu, A. Baran, and D. F. Anghel, "Effect of organic solvents upon the basic hydrolysis of acetylsalicylic acid in aqueous-micellar solutions," Romanian Journal of Chemistry, vol. 50, no. 9-10, pp. 767-775, 2005.

[12] Y. S. Simanenko, A. F. Popov, T. M. Prokopeva, E. A. Karpichev, I. A. Belousova, and V. A. Savelova, "Micellar effects of cationic detergents in the decomposition of ecotoxic substrates by hydroxide ion," Theoretical and Experimental Chemistry, vol. 38, no. 4, pp. 242-249, 2002.

[13] L. Mukherjee, N. Mitra, P. K. Bhattacharya, and S. P. Moulik, "Kinetics in microemulsion medium. 4. Alkaline fading of crystal violet in aqueous $\left(\mathrm{H}_{2} \mathrm{O} /\right.$ aerosol OT/isooctane and $\mathrm{H}_{2} \mathrm{O} /$ aerosol OT/decane) and nonaqueous (ethylene glycol/ aerosol OT/isooctane) microemulsions," Langmuir, vol. 11, no. 8, pp. 2866-2871, 1995.

[14] R. Y. Talman, S. Göktürk, and M. Tunçay, "Kinetic cosolvent effects on the alkaline fading of crystal violet in the presence of sodium dodecyl sulfate micelles," Colloids and Surfaces A: Physicochemical and Engineering Aspects, vol. 270-271, no. 1-3, pp. 72-77, 2005.
[15] J. Datta, A. Bhattiacharya, and K. K. Kundu, "Effect of surfactants on the kinetics of alkaline fading of crystal violet and acidcatalyzed inversion of sucrose," Indian Journal of Chemistry, vol. 27, pp. 115-122, 1988.

[16] C. Dolcet and E. Rodenas, "Hydroxide ion specific adsorption on cetyltrimethylammonium bromide micelles explains kinetic data," Colloids and Surfaces A: Physicochemical and Engineering Aspects, vol. 75, pp. 39-50, 1993.

[17] E. F. J. Duynstee and E. Grunwald, "Organic reactions occurring in or on micelles. I. Reaction rate studies of the alkaline fading of triphenylmethane dyes and sulfonphthalein indicators in the presence of detergent salts," Journal of the American Chemical Society, vol. 81, no. 17, pp. 4540-4542, 1959.

[18] I. Molinero, M. L. Sierra, M. Valiente, and E. Rodenas, "Physical properties of cetylpyridinium chloride micelles and their behaviour as reaction media," Journal of the Chemical SocietyFaraday Transactions, vol. 92, no. 1, pp. 59-63, 1996.

[19] Y. Zhang, X. Li, J. Liu, and X. Zeng, "Micellar catalysis of composite reactions-the effect of SDS micelles and premicelles on the alkaline fading of crystal violet and malachite green," Journal of Dispersion Science and Technology, vol. 23, no. 4, pp. 473-481, 2002.

[20] A. M. R. Kabir and M. A. B. H. Susan, "Kinetics of the alkaline hydrolysis of crystal violet in aqueous solution influenced by anionic surfactants," Journal of Saudi Chemical Society, vol. 12, pp. 543-554, 2008.

[21] C. O. Rangel-Yagui, A. Pessoa Jr., and L. C. Tavares, "Micellar solubilization of drugs," Journal of Pharmacy and Pharmaceutical Sciences, vol. 8, no. 2, pp. 147-165, 2005.

[22] P. C. Mohr, A. Mohr, T. P. Vila, and H.-G. Korth, "Localization of hydrophobic N-diazeniumdiolates in aqueous micellar solution," Langmuir, vol. 26, no. 15, pp. 12785-12793, 2010.

[23] M. N. Khan, P. C. Gleen, and Z. Arifin, "Effects of inorganic salts and mixed aqueous-organic solvents on the rates of alkaline hydrolysis of aspirin," Indian Journal of Chemistry, vol. 35, no. 9, pp. 758-765, 1996.

[24] M. E. Moro, J. Novillo-Fertrell, M. M. Velazquez, and L. J. Rodriguez, "Kinetics of the acid hydrolysis of diazepam, bromazepam, and flunitrazepam in aqueous and micellar systems," Journal of Pharmaceutical Sciences, vol. 80, no. 5, pp. 459-468, 1991.

[25] M. Ferrit, C. Del Valle, M. López, R. Luque, and F. Martínez, "The Stability of 2-Acetoxy-4-trifluoromethylbenzoic acid (Triflusal) in micellar Pseudophase," Journal of Pharmaceutical Sciences, vol. 93, no. 2, pp. 461-469, 2004.

[26] C. Matos, H. Chaimovich, J. L. Lima, I. M. Cuccovia, and S. Reis, "Effect of liposomes on the rate of alkaline hydrolysis of indomethacin and acemetacin," Journal of Pharmaceutical Sciences, vol. 90, no. 3, pp. 298-309, 2001.

[27] N. P. Gensmantel and M. I. Page, "The micelles catalyzed hydrolysis of penicillin derivatives (Part I) and the effect of increasing the hydrophobicity of penicillin on its micellecatalyzed hydrolysis (Part II)," Journal of the Chemical Society Perkin Transactions, vol. 2, pp. 147-155, 1982.

[28] A. Cipiciani, C. Ebert, R. Germani et al., "Micellar effects on the basic hydrolysis of indomethacin and related compounds," Journal of Pharmaceutical Sciences, vol. 74, no. 11, pp. 1184-1187, 1985.

[29] M. H. M. Leung, H. Colangelo, and T. W. Kee, "Encapsulation of curcumin in cationic micelles suppresses alkaline hydrolysis," Langmuir, vol. 24, no. 11, pp. 5672-5675, 2008. 
[30] A. S. Al-Ayed, M. S. Ali, H. A. Al-Lohedan, A. M. Al-Sulaim, and Z. A. Issa, "Effect of alkyl chain length, head group and nature of the surfactant on the hydrolysis of 1,3-benzoxazine2,4-dione and its derivatives," Journal of Colloid and Interface Science, vol. 361, no. 1, pp. 205-211, 2011.

[31] J. E. Dawson, B. R. Hajratwala, and H. Taylor, "Kinetics of indomethacin degradation II: presence of alkali plus surfactant," Journal of Pharmaceutical Sciences, vol. 66, no. 9, pp. 1259-1263, 1977.

[32] A. G. Oliveira, I. M. Cuccovia, and H. Chaimovich, "Micellar modification of drug stability: analysis of the effect of hexadecyltrimethylammonium halides on the rate of degradation of cephaclor," Journal of Pharmaceutical Sciences, vol. 79, no. 1, pp. 37-42, 1990.

[33] A. S. Al-Ayed, M. S. Ali, H. A. Al-Lohedan, A. M. Al-Sulaim, and Z. A. Issa, "Micellar effects on the alkaline hydrolysis of isatin and its derivatives," Journal of Colloid and Interface Science, vol. 357, no. 2, pp. 393-399, 2011.

[34] M. Ferrit, C. del Valle, and F. Martínez, "The study of the influence of surfactant charge on alkaline hydrolysis reactions of acetylsalicylic acid (ASA) and triflusal (TFL) using spectrophotometric methods," European Journal of Pharmaceutical Sciences, vol. 31, no. 3-4, pp. 211-220, 2007.

[35] M. Arias, L. García-Río, J. C. Mejuto, P. Rodríguez-Dafonte, and J. Simal-Gándara, "Influence of micelles on the basic degradation of carbofuran," Journal of Agricultural and Food Chemistry, vol. 53, no. 18, pp. 7172-7178, 2005.

[36] F. Begum, M. Y. A. Mollah, M. M. Rahman, and M. A. B. H. Susan, "Kinetics of the alkaline hydrolysis of crystal violet in micelles, reverse micelles and microemulsions of cetyltrimethylammonium bromide," Journal of the Bangladesh Chemical Society, vol. 24, pp. 173-184, 2011.

[37] M. N. Khan, Micellar Catalysis (Surfactant Science), CRC Press, Boca Raton, Fla, USA, 2006.

[38] B. K. Paul and S. P. Moulik, "The viscosity behaviours of microemulsions: an overview," Proceeding of Indian National Science Academy Part A, vol. 66, pp. 499-519, 2000.

[39] A. Zvonar, B. Rozman, M. B. Rogac, and M. Gasperlin, "The influence of microstructure on celecoxib release from a pharmaceutically applicable system," Acta Chimica Slovenica, vol. 56, no. 1, pp. 131-138, 2009.

[40] M. Goffredi, V. T. Liveri, and G. Vassallo, "Refractive index of water-AOT-n-heptane microemulsions," Journal of Solution Chemistry, vol. 22, no. 10, pp. 941-949, 1993.

[41] Y.-S. Rhee, J.-G. Choi, E.-S. Park, and S.-C. Chi, “Transdermal delivery of ketoprofen using microemulsions," International Journal of Pharmaceutics, vol. 228, no. 1-2, pp. 161-170, 2001.

[42] K. Zielińska, K. A. Wilk, A. Jezierski, and T. Jesionowski, "Microstructure and structural transition in microemulsions stabilized by aldonamide-type surfactants," Journal of Colloid and Interface Science, vol. 321, no. 2, pp. 408-417, 2008. 

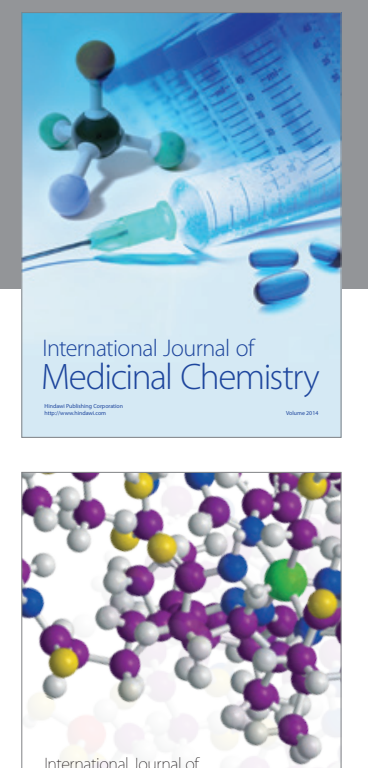

\section{Carbohydrate} Chemistry

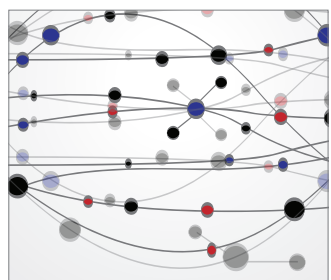

The Scientific World Journal
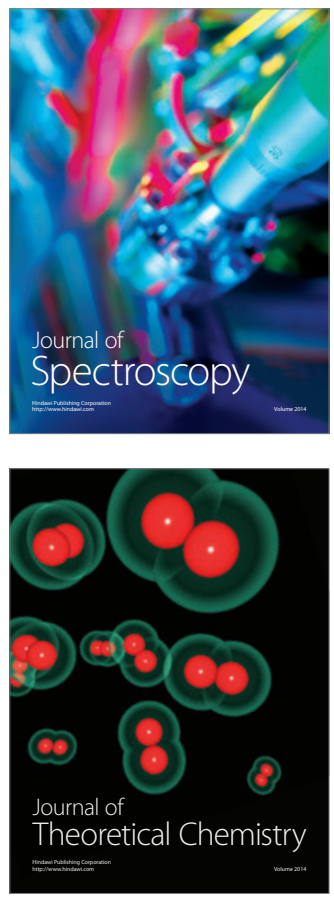
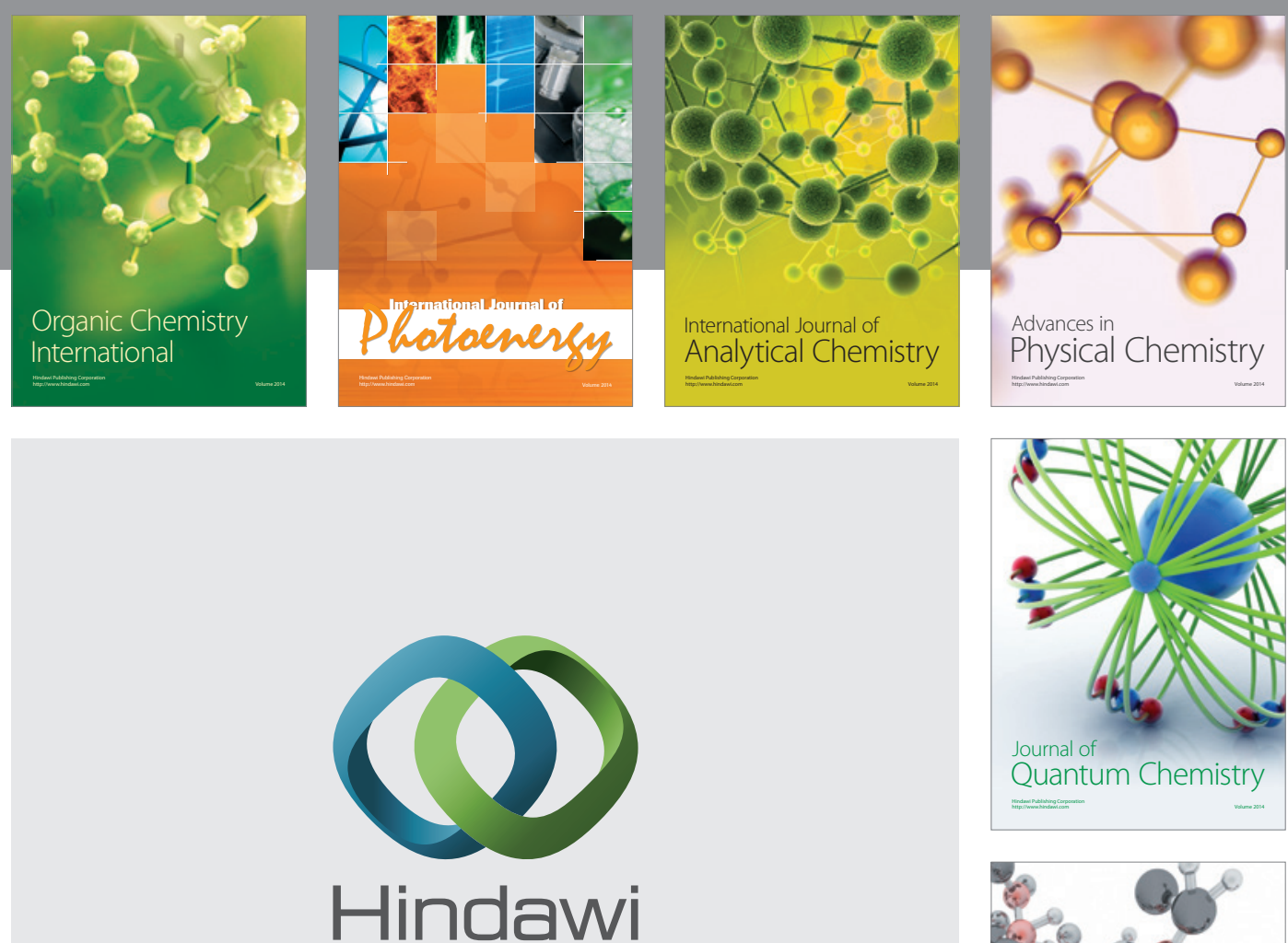

Submit your manuscripts at

http://www.hindawi.com

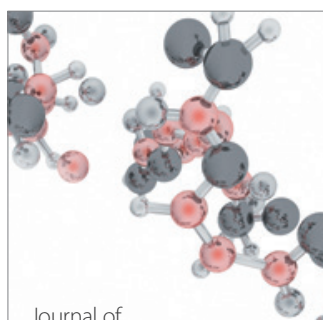

Analytical Methods

in Chemistry

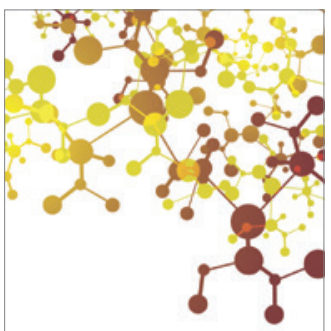

Journal of

Applied Chemistry

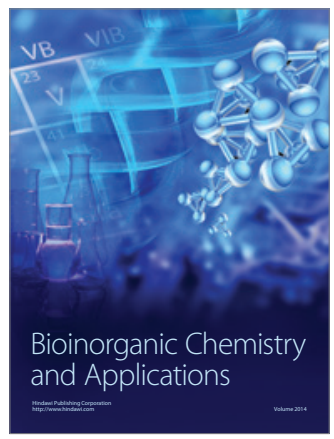

Inorganic Chemistry
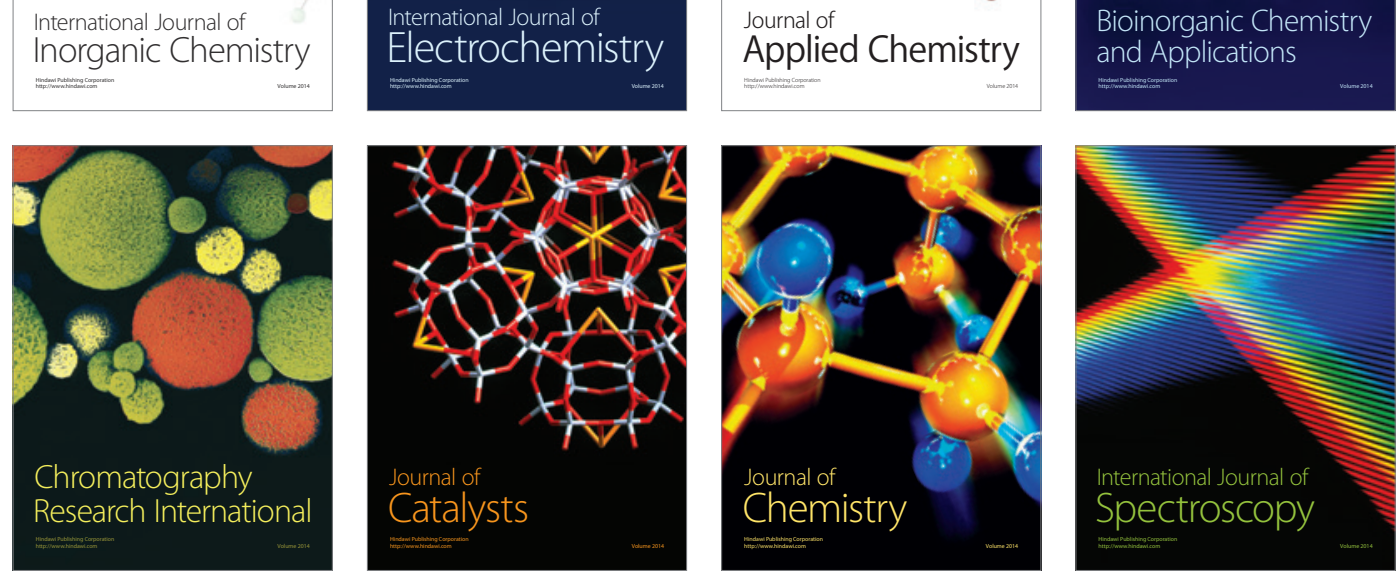